groups to define a normal range and to determine whether a decreased ratio could be used as a screening test to identify intrauterine growth retardation.

\section{Subjects and methods}

All infants studied were judged full term on the basis of the Parkin score, performed in the first 24 hours of life. The birth weight and ethnic group were recorded. The study was carried out over two periods of three months In the first three months the mid-arm circumference and occipitofrontal circumference were measured on the third day of life of all babies admitted to the postnatal wards. Measurements were taken with a non-stretch plastic tape measure. The mid-arm circumference was taken at the point halfway between the acromion and the olecranon process of the ulna on the right arm, which was flexed at $90^{\circ}$. The occipitofrontal circumference was taken as the largest circumference of the skull. The coefficient of variation of the method, assessed by making 10 measurements of one child on the same day, was found to be $2 \cdot 0 \%$. The interobserver coefficient of variation (four observers each made 10 measurements of the same child) was $2 \cdot 5 \%$. A mean ratio for each ethnic group was determined and abnormal values defined as those that varied from the mean by $>2$ SD. Data were compared by Student's $t$ test. During the second study only those infants whose birth weight fell below the 10th percentile on the charts derived by Gairdner were measured. Clinical symptoms were recorded, together with any correlation between them and an abnormal ratio of mid-arm circumference to occipitofrontal circumference.

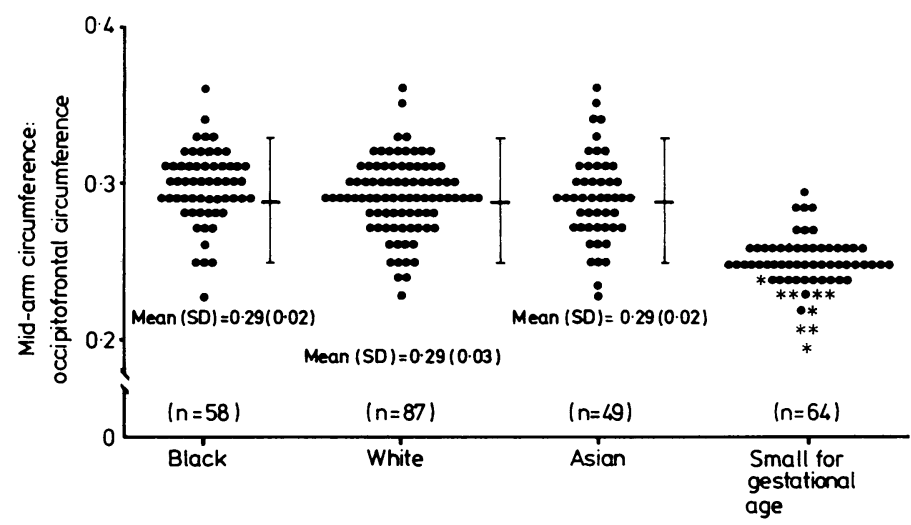

Ratio of mid-arm circumference to occipitofrontal circumference in ethnic groups and all infants small for gestational age.

$\star$ Symptomatic infants.

\section{Results}

The mean birth weights of the three ethnic groups showed no significant difference (black 3090 (SD 440) $\mathrm{g}(\mathrm{n}=58)$; white 3180 (510) $\mathrm{g}(\mathrm{n}=87)$; Asian $\stackrel{\Phi}{\circ}$ $2900(360) \mathrm{g}(\mathrm{n}=49))$, but seven black (12\%), six white $(7 \%)$, and 10 Asian $\mathrm{C}$ $(20 \%)$ babies had birth weights below the 10th percentile, suggesting that a higher proportion of Asian babies had suffered intrauterine growth retardation. In contrast the ratio of mid-arm circumference to occipitofrontal circumference did not differ significantly among the three groups (figure); $\mathbb{\mathbb { D }}$ 11 babies had values $>2$ SD below the mean and all showed evidence of wasting, though two had weights above the 10th percentile on standard 2 charts. Of the 64 neonates below the 10th percentile for weight, $20(32 \%)$ had $\%$ a ratio of mid-arm circumference to occipitofrontal circumference $>2$ SD $\overrightarrow{\vec{D}}$ below the mean (figure). Nine of these 21 infants developed symptoms: six had low blood glucose concentrations $(<2 \mathrm{mmol} / 1(<36 \mathrm{mg} / 100 \mathrm{ml}))$, seven had poor temperature control $\left(36^{\circ} \mathrm{C}\right)$, and one developed necrotising $\frac{\bar{F}}{\bar{\omega}}$ enterocolitis.

\section{Discussion}

Accurate identification of intrauterine growth retardation is $\overrightarrow{\vec{\omega}}$ important if complications such as early hypoglycaemia, poor $\stackrel{\circ}{\circ}$ temperature control, and sepsis are to be avoided. ${ }^{4}$ Many cities now $\frac{5}{3}$ have a multiethnic population, and the application of weight standards alone may be inappropriate. The ratio of mid-arm $\mathbb{N}$ circumference to occipitofrontal circumference has been used to $\dot{\sigma}$ indicate malnutrition in older children ${ }^{5}$; our study found that this $N$ ratio shows no intraethnic variation and can be used as a reliable and $:$ simple screening test to identify babies whose growth is retarded, even when their weight does not fall below the 10th percentile. 0 Those babies whose occipitofrontal circumference is reduced 을 because of proportionate growth retardation might not be identi- $\overrightarrow{0}$ fied, but they do not have the same risk of hypoglycaemia. Similarly, babies with hydrocephalus may give a falsely low reading.

\section{References}

1 Simmons $\mathrm{K}$, Savage $\mathbf{W}$, Nicholls $\mathbf{B}$, Rao U. Fetal growth measured by ultrasound in Bengali women. Foumal of Obstetrics and Gynaecology 1985;5:233-6.

Jore OG. Fetal growth in different racial groups. Arch Dis Child 1978.53: $27-32$

3 Clarson CL, Barher MJ, Marshall T, Wharton BA. Secular changes in birth weight of Asian babies born in Birmingham. Arch Dis Child 1982;57:867-71

4 Wallis S, Harvey D. Small-for-dates babies, after problems and their future. In: Wharton B, ed. $\overline{\overline{\mathbf{O}}}$ Topics in perinatal medicine. Tunbridge Wells: Pitman Medical, 1980.

5 Kanawati A, McLaren D. Assessment of marginal malnutrition. Nature 1970;228:573-4.

(Accepted 4 February 1986

\title{
100 YEARS AGO
}

"Sir,-Having read your learned discourse on the subject of the higher education of women, I beg, though rather late, to thank you, on my own behalf and that of my sex generally, for your very high opinion of us, as expressed at the meeting of the British Medical Association; though I must confess that it is somewhat new and startling to learn that women were created solely for the purpose of propagating the human species, and, as such, for the mere convenience of that glorious creature 'man,' as represented by your own illustrious self. It may perhaps be showing my great ignorance and inferiority when $\mathrm{I}$, as a woman, repudiate your highly flattering suggestions, and not only entirely and emphatically deny the truth of them (though you are such a very distinguished medical man), and assert that, having been created with an equal intellect as man's, and with an equal love of knowledge and independence, that in itself proves the utter fallacy of your disgusting theory. Of course, every one is aware that medical men are threatened with the loss of quite half of their practice by the admission of women into the profession, as their women patients would of course gladly give the preference to their own sex, when they have the opportunity; and as medical gentlemen are by no means indifferent to the question of pounds, shillings, and pence, it is not so much wonder that they express such horror at the prospect of their fat incomes being endangered. Though, however, on this account they may deserve some pity, yet that alone will not be sufficient to preserve them from the ridicule and contempt excited by their miserable efforts to exclude women from the medical profession, the sordid motive for doing so being too palpable. Therefore, before saying adieu, let me give you $G$ one piece of advice, which is that, in your future opposition to the progress of $D$ women, not at any rate to repeat the disgusting, and insulting, and ignorant remarks on my sex, or else you may perhaps find by bitter experience that, $\bar{N}$ though women are, as you make them out to be, on a level with the beasts of $\mathrm{N}$ the field, they may yet be capable of showing their resentment at being told $\omega$ so by administering a sound chastisement on the offender, even though he may occupy the important position of President of the British Medicalo Association, or of any other ridiculous and trumpery association.-Your $\frac{\text { C }}{\mathbb{D}}$ obedient servant, (British Medical fournal 1886;ii:426.)

\section{Correction}

Synthesis of histamine by Haemophilus influenzae

We regret that an error occurred in this paper by Dr Bryan D Sheinman et al, 29 응 March, p 857. The second sentence of the abstract should have read: "Ten isolates of Haemophilus influenzae . . were incubated at $37^{\circ} \mathrm{C}$ for 48 hours," not "for 72 hours." 